\title{
Vascular Calcification in Chronic Kidney Disease is Induced by Bone Morphogenetic Protein-2 via a Mechanism Involving the Wnt/ $\beta$-Catenin Pathway
}

\author{
Shu Rong ${ }^{a}$ Xuezhi Zhao ${ }^{b}$ Xiucai Jin ${ }^{c}$ Zheng Zhang ${ }^{a}$ Lei Chen ${ }^{a} \quad$ Yuxian Zhu ${ }^{b}$ \\ Weijie Yuan ${ }^{\mathrm{a}}$ \\ aDepartment of Nephrology, Shanghai Jiaotong University Affiliated First People's Hospital, \\ bDepartment of Nephrology, Shanghai Changzheng Hospital, Second Military Medical University, \\ 'Department of Ultrasound, Shanghai Changhai Hospital, Second Military Medical University, Shanghai, \\ China
}

\section{Key Words}

Bone morphogenetic protein-2 Vascular calcification - Wnt/ $\beta$-catenin signaling pathway $•$ Chronic kidney disease

\begin{abstract}
Background: Vascular calcification (VC), in which vascular smooth muscle cells (VSMCs) undergo a phenotypic transformation into osteoblast-like cells, is one of the emergent risk factors for the accelerated atherosclerosis process characteristic of chronic kidney disease (CKD). Phosphate is an important regulator of VC. Methods: The expression of different smooth muscle cell or osteogenesis markers in response to high concentrations of phosphate or exogenous bone morphogenetic protein 2 (BMP-2) was examined by qRT-PCR and western blotting in rat VSMCs. Osteocalcin secretion was measured by radioimmunoassay. Differentiation and calcification of VSMCs were examined by alkaline phosphatase (ALP) activity assay and Alizarin staining. Short hairpin RNA-mediated silencing of $\beta$-catenin was performed to examine the involvement of Wnt/ $\beta$-catenin signaling in VSMC calcification and osteoblastic differentiation induced by high phosphate or BMP-2. Apoptosis was determined by TUNEL assay and immunofluorescence imaging. Results: BMP-2 serum levels were significantly higher in CKD patients than in controls. High phosphate concentrations and BMP-2 induced VSMC apoptosis and upregulated the expression of $\beta$-catenin, Msx2, Runx2 and the phosphate cotransporter Pit1, whereas a BMP-2 neutralization antibody reversed these effects. Knockdown of $\beta$-catenin abolished the effect of high phosphate and BMP-2 on VSMC apoptosis and calcification. Conclusions: BMP-2 plays a crucial role in calcium deposition in VSMCs and VC in CKD patients via a mechanism involving the $\mathrm{Wnt} / \beta$-catenin pathway.
\end{abstract}

Copyright $\odot 2014$ S. Karger AG, Basel

Weijie Yuan

and Xiucai Jin
Department of Nephrology, Shanghai Jiaotong University Affiliated First People's Hospital, No. 100, Haining road, Hongkou District, Shanghai 200080 (China) E-Mail yuanweijie@yeah.net, E-Mail goldenxc@126.com 


\section{Cellular Physiology and Biochemistry}

Cell Physiol Biochem 2014;34:2049-2060

\begin{tabular}{l|l}
\hline DOI: $10.1159 / 000366400$ & (C) 2014 S. Karger AG, Basel
\end{tabular}

Published onlıne: November 28, 2014

www.karger.com/cpb

Rong et al.: BMP-2 and Wnt/ $\beta$-Catenin Pathway in CKD

\section{Introduction}

Vascular calcification (VC) is the deposition of calcium phosphate crystals in cardiovascular tissues [1]. In the past, VC was considered a passive and degenerative process [2]. However, recent evidence led to its recognition as a pathobiological process sharing features with embryonic bone formation, which promoted an increased interest in the study of $\mathrm{VC}$ and its clinical implications [3]. It is currently recognized as a process similar to that of bone development in which different factors interact in response to mechanical, inflammatory and morphogenetic signals governing skeletal, or in this case arterial, mineralization. The result is a reduction of arterial elastance and impairment of cardiovascular hemodynamics leading to hypertension, aortic stenosis, cardiac hypertrophy and other cardiovascular diseases [2]. The pathogenesis of VC is complex and involves a process by which vascular smooth muscle cells (VSMCs) undergo apoptosis and are transformed into osteoblast-like cells, releasing matrix vesicles with the capacity to concentrate calcium and phosphate, promoting mineralization [4].

Phosphate is an important regulator of VC and high serum phosphate levels are an important risk factor for cardiovascular mortality in CKD patients [5, 6]. High levels of extracellular phosphate have been linked to processes that regulate arterial medial calcification such as VSMC apoptosis and osteogenic differentiation. During their phenotypic transition into osteoblast-like cells, VSMCs cease to express smooth muscle markers such as smooth muscle alpha actin ( $\alpha$-SMA) and SM22 and instead express bone-forming genes such as Runx2/Cbfa1, alkaline phosphatase, osteopontin and osteocalcin $[7,8]$. The active transport of phosphate into cells is mediated by three types of sodium-dependent phosphate transporters, of which the type III transporters Pit1 and Pit2 are ubiquitously expressed and are the predominant phosphate transporters in humans, and Pit1 is required for the osteogenic differentiation of VSMCs $[9,10]$. In patients with chronic kidney disease (CKD), disseminated and fast-progressing calcification of the vascular system is associated with cardiovascular disease and increased mortality [11-13]. Structural and functional alterations of the cardiovascular system such as endothelial dysfunction, arterial stiffening and VC contribute to the risk of cardiovascular disease in CKD patients [14], and arterial remodeling involves several bone-associated proteins such as osteocalcin, osteopontin and bone morphogenetic proteins (BMPs) that are expressed in calcified arterial lesions $[15,16]$.

Wnt signaling, which plays a critical role in the commitment of pluripotent mesenchymal cells, is activated during VC [17]. Wnt proteins bind to a coreceptor complex formed by proteins of the frizzled (Fzd) family and lipoprotein receptor related $5 / 6$ proteins (Lrp5/6). In the canonical Wnt pathway, the inactivation of a destruction complex that targets $\beta$-catenin for proteasomal degradation results in the translocation of $\beta$-catenin to the nucleus to regulate the expression of target genes [18]. The activation of $\beta$-catenin signaling modulates the proliferation and differentiation of osteoblasts $[19,20]$. Wht signaling promotes osteogenesis through the stimulation of Runx2 expression [21]. BMPs and Wnt ligands have been implicated in the regulation of the osteoblastic transdifferentiation of VSMCs, and a BMP-Wnt/ $\beta$-catenin axis has been implicated in the osteogenic regulation of VC [22-24].

In the present study, we examined the link between VC in CKD and the expression of BMPs, and explored the underlying mechanisms. Our results indicate that BMP-2 promotes the osteogenic differentiation of VSMCs via a mechanism involving the Wnt/ $\beta$-catenin signaling pathway, suggesting a potential mechanism of VC in CKD and providing novel therapeutic targets for the treatment of patients with kidney diseases.

\section{Materials and Methods}

Patients

Ninety-one CKD patients including 46 men and 45 women aged 25-81 years (mean age, $58.19 \pm$ 17.35 years) were recruited from the Nephrology Department at Shanghai Changzheng Hospital between 


\section{Cellular Physiology and Biochemistry}

Cell Physiol Biochem 2014;34:2049-2060

\begin{tabular}{l|l}
\hline DOI: $10.1159 / 000366400$ & (c) 2014 S. Karger AG, Basel
\end{tabular}

www.karger.com/cpb

Rong et al.: BMP-2 and Wnt/ $\beta$-Catenin Pathway in CKD

January 2013 and February 2014. The patient diagnoses are summarized in Table 1. Thirty-five healthy subjects with normal renal function were selected as the control group. The present study was approved by the local investigational Hy
review board and written informed consent was obtained from all participants.

\section{Samples and analysis}

Table 1. Patint renal diagnoses

\begin{tabular}{lll}
\hline Diagnosis & $\mathrm{n}$ & $\%$ \\
\hline Chronic glomerulonephritis & 41 & 45.05 \\
Hypertensive nephrosclerosis & 20 & 21.98 \\
Diabetic nephropathy & 18 & 19.78 \\
Polycystic kidney disease & 3 & 3.30 \\
Obstructive nephropathy & 1 & 1.10 \\
Other & 8 & 8.79 \\
\hline
\end{tabular}

Blood samples were collected in serum separator tubes from patients and healthy participants, centrifuged at $1,000 \mathrm{~g}$ for $10 \mathrm{~min}$ and serum was stored at $-70^{\circ} \mathrm{C}$ until evaluation. All samples were analyzed simultaneously. Serum BMP-2 levels were measured using a commercially available ELISA kit (R\&D System, Minneapolis, MN, USA) according to the manufacturer's instructions.

\section{VSMCs culture and treatments}

Animal experimental procedures were approved by the Animal Care and Use Committee of Shanghai Changzheng Hospital. VSMCs were isolated from the thoracic aorta of male Sprague-Dawley (SD) rats ( $n=5$, 8-10 weeks) using the explants technique, and cultured in M199 (Gibco, NY, USA) with 10\% fetal bovine serum (FBS) (Gibco) and $1 \%$ penicillin/streptomycin at $37^{\circ} \mathrm{C}$ in $5 \% \mathrm{CO}_{2}$. Immunocytochemical staining with $\alpha$-SMA antibody ( $\alpha$-SMA; Dakopatt, Copenhagen, Denmark) showed that more than $90 \%$ of the cells in culture were VSMCs.

Primary VSMCs were seeded onto 12 -well plates $\left(1 \times 10^{6} / \mathrm{ml}\right)$ and grown to confluence. Cells were synchronized by serum deprivation for $24 \mathrm{~h}$ before the addition of ionic phosphate $\left(\mathrm{NaH}_{2} \mathrm{PO}_{4}\right.$ was used to supplement ionic phosphate) or BMP-2 in fresh serum-free medium. VSMCs were treated with different phosphate concentrations $(0,1.5,2.5$ or $3.5 \mathrm{mM})$ for 3 days to determine BMP-2 levels or for different times to measure calcium deposition, and with $50 \mathrm{ng} / \mathrm{ml} \mathrm{BMP}-2$ [25] or $2.5 \mathrm{mM}$ phosphate for 3 days, or pretreated with a BMP-2 neutralization antibody ( $2 \mu \mathrm{g} / \mathrm{ml}$, R\&D Systems, Minneapolis, Minn., USA) for $30 \mathrm{~min}$.

\section{Western blot analysis}

Protein lysates were prepared from VSMCs using a lysis buffer $(10 \mathrm{mmol} / \mathrm{L} \mathrm{HEPES}, 10 \mathrm{mmol} / \mathrm{L} \mathrm{KCl}, 0.1$ $\mathrm{mmol} / \mathrm{L}$ EDTA, $0.1 \mathrm{mmol} / \mathrm{L}$ EGTA, $1 \mathrm{mmol} / \mathrm{L}$ dithiothreitol, $0.5 \mathrm{mmol} / \mathrm{L}$ PMSF, $70 \mathrm{mg} / \mathrm{ml}$ protease inhibitor cocktail and 0.6\% Igepal CA-630, pH 7.9). Protein concentration was determined using the BCA protein Assay Kit (Beyotime, Jiangsu, China). Proteins were separated on 8-10\% SDS-polyacrylamide gels (Invitrogen, Carlsbad, CA) and transferred to nitrocellulose membranes (Invitrogen). Membranes were blocked with $5 \%$ nonfat dried milk in PBS for $1 \mathrm{~h}$ at room temperature followed by incubation in primary antibody for $2 \mathrm{~h}$ at room temperature. Primary antibodies and dilutions were as follows: anti-BMP-2 (1/500), anti-SM $22 \alpha(1 / 200)$, anti- $\alpha$-SMA (1/200), anti- $\beta$-catenin (1/500), anti-Msx2 $(1 / 200)$, anti-Runx2 (1/200), antiPit1 (1/500), anti-GAPDH (1/1000). All antibodies were purchased from Abcam. Secondary antibodies were goat polyclonal anti-rabbit IgG - H\&L - Pre-Adsorbed (HRP) at 1/2000 dilution. Blots were developed on autoradiographic film using the ECL Plus western blotting detection system (Amersham Biosciences, Little Chalfont, England). Densitometric values were determined using a gel image analysis system (BioRad, Hercules, CA).

\section{Calcium deposition}

For assessment of calcium deposition, cells were first decalcified in $\mathrm{HCl}(0.6 \mathrm{~mol} / \mathrm{L})$ for $24 \mathrm{~h}$. The calcium content was determined by measuring the concentration of calcium in the $\mathrm{HCl}$ supernatant by atomic absorption spectroscopy and normalized to the protein content of cells measured using the BCA protein Assay Kit after solubilization in $0.1 \mathrm{M} \mathrm{NaOH} / 0.1 \%$ sodium dodecyl sulfate.

Terminal deoxynucleotidyl transferase dUTP nick end labeling (TUNEL) assay

Apoptosis was measured using the TUNEL cell apoptosis detection kit (Beyotime). VSMCs were cultured in 6-well plates and treated as indicated, fixed with $4 \%$ paraformaldehyde in PBS, rinsed twice with PBS, and permeabilized using $0.1 \%$ Triton X-100. Cells were then subjected to TUNEL staining for $1 \mathrm{~h}$ at $37^{\circ} \mathrm{C}$. FITC-labeled TUNEL-positive cells were imaged by fluorescent microscopy at wavelengths of 488 $\mathrm{nm}$ excitation and $530 \mathrm{~nm}$ emission. Nuclei were stained by DAPI. 


\section{Cellular Physiology and Biochemistry}

Cell Physiol Biochem 2014;34:2049-2060

\begin{tabular}{l|l}
\hline DOI: $10.1159 / 000366400$ & (c) 2014 S. Karger AG, Basel
\end{tabular}

www.karger.com/cpb

Rong et al.: BMP-2 and Wnt/ $\beta$-Catenin Pathway in CKD $\beta$-catenin shRNA and transfection

To generate an shRNA-expression plasmid, two pairs of shRNA sequences and one pair of scrambled sequences were designed according to the rat $\beta$-catenin nucleotide sequence obtained from GeneBank. The targeting nucleotide sequences were as follows: $\beta$-catenin shRNA1, 5'-AACAGTCTTACCTGGACTCTG-3'; $\quad \beta$-catenin ShRNA2, 5 '-GGTGCTGACTATCCAGTTGA-3'; scrambled shRNA, 5'-TTCTCCGAACGTGTCACGT-3'. Each shRNA sequence was inserted into the pLVTHM lentiviral vector (Sigma) at the MluI/ ClaI site. pLVTHM- $\beta$-catenin shRNA1, pLVTHM$\beta$-catenin shRNA2 and pLVTHM- scrambled shRNA were co-transfected with the packaging
Table 2. Primers used in real time RT-PCR analysis

\begin{tabular}{ll}
\hline Primer & Sequence (5' to 3') \\
\hline$\beta$-catenin - F & AGATGCAGCAACTAAACAGGA \\
$\beta$-catenin - R & GTACTACATTTTAAGCCATCT \\
SM 22a - F & TGAACAGCCTGTACCCCGAG \\
SM 22a - R & CTCTGCACTGCTGCCATATCT \\
osteocalcin - F & CAAAGCCCAGCGACTCTGA \\
osteocalcin - R & TCCATTGTTGAGGTAGCGCC \\
Msx2 - F & GTCCGGGACGCTCACAGTC \\
Msx2 - R & GAACTTGCGCTCCAAGGCTA \\
Runx2 - F & AGCTATTAAAGTGACAGTGGACG \\
Runx2 - R & GAGGATTGTGTCTGCCTGGG \\
Pit1 - F & CAAAGATGGCTCCTGGCGA \\
Pit1 - R & GGTTGCTGACGGTTTGACTG \\
GAPDH - F & CGCTAACATCAAATGGGGTGA \\
GAPDH - R & CAGGATGCATTGCTGACAATC \\
\hline
\end{tabular}

vector psPAX2 and the envelope vector pMD2.G into 293T cells using Lipofectamine ${ }^{\mathrm{TM}} 2000$ and $24 \mathrm{~h}$ after transfection, media containing virus were harvested from transfected 293T cells. VSMCs were incubated with lentivirus medium. After three infections, GFP-positive cells were sorted by flow cytometry. The expression of $\beta$-catenin in GFP-positive VSMCs was determined by quantitative real-time PCR (qRT-PCR) and western blotting. The empty vector PLVTHM or PLVTHM-scrambled shRNA served as negative control.

qRT-PCR

Total RNA was isolated from cells using the Trizol reagent (Invitrogen), and cDNA synthesis was performed using the First-Strand cDNA synthesis kit (Invitrogen). Quantitative PCR was performed using a LightCycler (Roche) and the FastStart DNA Master Plus SYBR green I kit (Roche). The expression of target genes was normalized to that of GAPDH. Primers used for real time RT-PCR are shown in Table 2. PCR conditions were as follows: $95^{\circ} \mathrm{C}$ for $15 \mathrm{~s}, 57^{\circ} \mathrm{C}$ for $30 \mathrm{~s}$, and $72^{\circ} \mathrm{C}$ for $1 \mathrm{~min}$.

\section{Measurements of osteocalcin secretion}

Normal VSMCs or VSMCs transfected with scrambled shRNA or $\beta$-catenin shRNA1 were treated as indicated for 7 days. Osteocalcin secretion into the culture medium was measured using a radioimmunoassay kit (DiaSorin Corp., Stillwater, MN, USA) according to the manufacturer's instructions. Protein expression was normalized to total cellular protein using the BCA protein Assay Kit.

\section{Alkaline Phosphatase Assay}

VSMCs treated as indicated were washed and protein lysates were prepared using a lysis buffer (10 mM Tris-HCl, pH 7.5, 0.1\% Triton X-100). Alkaline phosphatase (ALP) activity was determined using p-nitro phenyl phosphate (Sigma-Aldrich) as a substrate. The hydrolyzation of the substrate by ALP yields a yellow colored product that was detected by measuring absorbance at $405 \mathrm{~nm}$.

\section{Alizarin red staining}

VSMCs treated as indicated for 14 days were washed, fixed with $4 \%$ paraformaldehyde in PBS for 15 min, stained with $2 \%$ Alizarin red S stain solution (Kanto Chemical, Japan) for 30 min at room temperature, washed three times and imaged under $200 \times$ bright field microscopy.

\section{Statistical analysis}

Data are representative of at least 3 independent experiments. The results are expressed as mean \pm SE. The significance of differences was estimated by ANOVA followed by Student's and Newmann-Keuls multiple comparison tests. All statistical analyses were performed using SPSS software (version 17.0, SPSS Inc., Chicago, IL). $\mathrm{p}<0.05$ was considered statistically significant. 


\section{Cellular Physiology and Biochemistry}

Cell Physiol Biochem 2014;34:2049-2060

\begin{tabular}{l|l}
\hline DOI: $10.1159 / 000366400$ & (C) 2014 S. Karger AG, Basel
\end{tabular}

www.karger.com/cpb

Rong et al.: BMP-2 and Wnt/ $\beta$-Catenin Pathway in CKD
Fig. 1. High phosphate promotes BMP-2 expression and calcium deposition in vascular smooth muscle cells. (A) Rat vascular smooth muscle cells (VSMCs) were treated with different phosphate concentrations for 3 days. BMP-2 protein expression was determined by western blotting and normalized to the levels of GAPDH. ${ }^{* *} \mathrm{p}<0.01$ compared to the control group (0 mM). (B) Rat VSMCs were treated with different phosphate concentrations for 1, 3, 5, 7 or 9 days and calcium deposition was measured. ${ }^{*} \mathrm{p}<0.05,{ }^{* *} \mathrm{p}<0.01$ compared to the $1.5 \mathrm{mM} \mathrm{PO}_{4}{ }^{3-}$ treatment group.

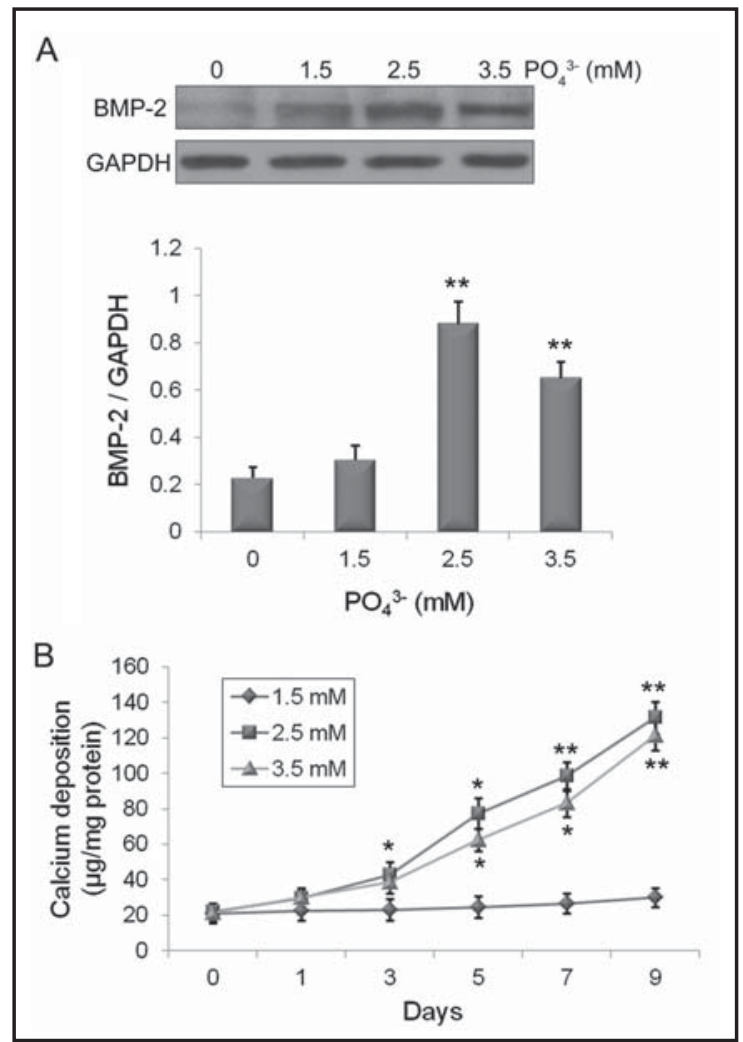

\section{Results}

Elevated serum BMP-2 levels in patients with chronic kidney disease

The association between CKD and VC was examined by measuring the levels of BMP-2 in 91 patients with CKD and 35 healthy controls. The mean serum BMP-2 concentration was significantly higher in CKD patients than in the controls $(86.49 \pm 5.70 \mathrm{vs} .35 .72 \pm 2.51 \mathrm{pg} / \mathrm{ml})$ $(\mathrm{p}<0.01)$. The characteristics of the subjects included in the analysis are shown in Table 1.

\section{High phosphate promotes BMP-2 expression and calcium deposition in VSMCs}

The effect of high phosphate on the expression of BMP-2 was examined in rat VSMCs exposed to increasing concentrations of phosphate. Western blot analysis showed a significant increase in the expression of BMP-2 in response to high phosphate concentrations (2.5 and $3.5 \mathrm{mM}$ ), with the strongest effect observed with $2.5 \mathrm{mM}$ phosphate for 3 days (Fig. 1A). Assessment of calcium deposition in response to different phosphate concentrations showed a significant time-dependent increase in calcium deposition in VSMCs after 3 days of treatment with 2.5 and $3.5 \mathrm{mM}$ phosphate, whereas no changes were observed in cells treated with $1.5 \mathrm{mM}$ phosphate (Fig. 1B). Therefore, a phosphate concentration of $2.5 \mathrm{mM}$ and 3 days of exposure were the conditions selected for further experiments assessing the effect of high phosphate on VSMC differentiation.

\section{High phosphate and BMP-2 promote VSMC calcification}

The effect of high phosphate and BMP-2 on the differentiation of VSMCs was examined in cells treated with $2.5 \mathrm{mM}$ phosphate, BMP-2 $(50 \mathrm{ng} / \mathrm{ml})$ or a BMP-2 neutralizing antibody $(2 \mu \mathrm{g} / \mathrm{ml}$ ) for 3 days. Western blot analysis showed that phosphate and BMP-2 significantly decreased the levels of the smooth muscle cell markers SM $22 \alpha$ and $\alpha$-SMA and significantly increased the levels of the osteogenesis markers Msx2, Runx2, Pit1 and $\beta$-catenin, and these effects were reversed by co-treatment with anti-BMP-2 (Fig. 2A and B). The effects of 


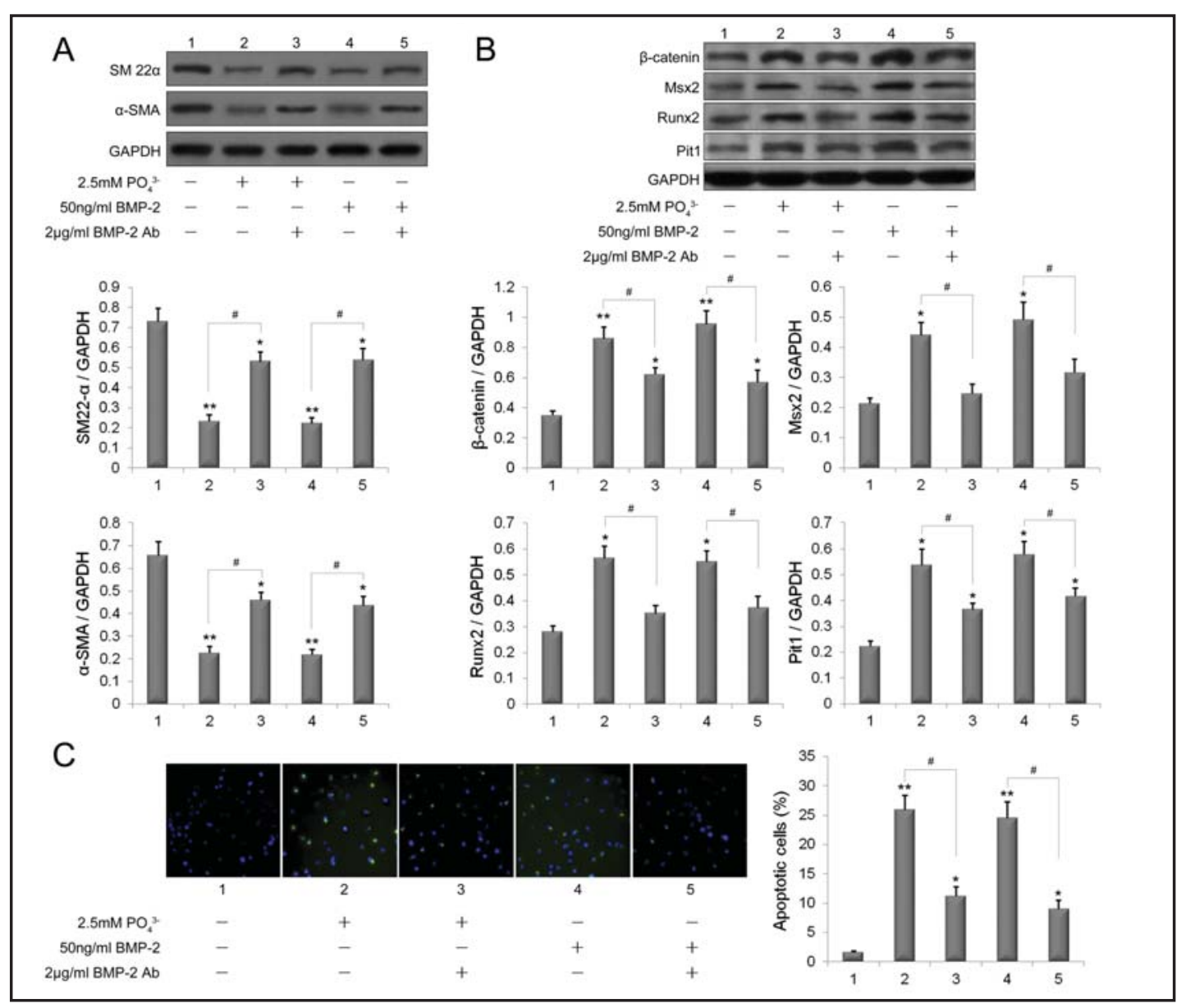

Fig. 2. High phosphate and BMP-2 promote calcification of vascular smooth muscle cells. VSMCs were treated as indicated for 3 days. The protein levels of (A) SM 22 $\alpha, \alpha$-SMA and (B) $\beta$-catenin, Msx2, Runx2, and Pit1 were determined by western blotting and normalized to the levels of GAPDH. ${ }^{*} p<0.05,{ }^{* *} p<0.01$ compared to the control group, $\# \mathrm{p}<0.05$. (C) Assessment of apoptosis in VSMCs by TUNEL assay and immunofluorescence staining. Representative images are shown (magnification, 200×). Nuclei are stained blue (DAPI) and TUNEL-positive cells are stained green. The percentages of apoptotic nuclei were calculated by determining the number of DAPI-stained nuclei that were also positive for TUNEL staining. ${ }^{*} \mathrm{p}<0.05,{ }^{* *} \mathrm{p}<0.01$ compared to the control group, $\# \mathrm{p}<0.05$.

phosphate and BMP-2 on apoptosis were examined using the TUNEL assay and fluorescent imaging. Figure 2C shows representative images of TUNEL staining in the different groups. Quantitative analysis of TUNEL positive cells showed that phosphate and BMP-2 caused a significant increase in the percentage of apoptotic cells from approximately $2 \%$ in the untreated controls to approximately $25 \%$ and $23 \%$, respectively $(\mathrm{p}<0.01)$ and co-treatment with anti-BMP-2 antibody significantly reversed this effect $(\mathrm{p}<0.05)$.

\section{Knockdown of $\beta$-catenin}

To examine the possible involvement of the Wnt/ $\beta$-catenin signaling pathway in mediating the effect of BMP-2, $\beta$-catenin expression was knocked down by infecting cells with lentiviral vectors carrying shRNAs targeting $\beta$-catenin for $48 \mathrm{~h}$. Both shRNA1 and shRNA2 significantly downregulated the mRNA (Fig. 3A) and protein (Fig. 3B) expressions of $\beta$-catenin compared to the empty vector or scrambled shRNA transfected controls $(p<0.01)$. Quantification of $\beta$-catenin levels by densitometry and normalization to the levels of GAPDH 


\section{Cellular Physiology and Biochemistry}

Cell Physiol Biochem 2014;34:2049-2060

\begin{tabular}{l|l}
\hline DOI: $10.1159 / 000366400$ & (C) 2014 S. Karger AG, Basel
\end{tabular}

www.karger.com/cpb

Rong et al.: BMP-2 and Wnt/ $\beta$-Catenin Pathway in CKD
Fig. 3. Effects of $\beta$-catenin knockdown. For $\beta$-catenin knockdown, VSMCs were infected with lentiviral vectors carrying shRNAs targeting $\beta$-catenin (shRNA1 or shRNA2) for $48 \mathrm{~h}$. Empty vector (pLVTHM) or scrambled shRNA in pLVTHM served as negative controls. (A) $\beta$-catenin mRNA was detected by qRT-PCR and normalized to GAPDH expression. Data are expressed as fold-change relative to the empty vector group. (B) $\beta$-catenin protein expression was determined by western blotting with GAPDH as the loading control. (C) Quantification of $\beta$-catenin protein levels was performed by densitometry and normalized to the level of GAPDH. ${ }^{*} \mathrm{p}<0.05,{ }^{* *} \mathrm{p}<0.01$ compared to the vector group.

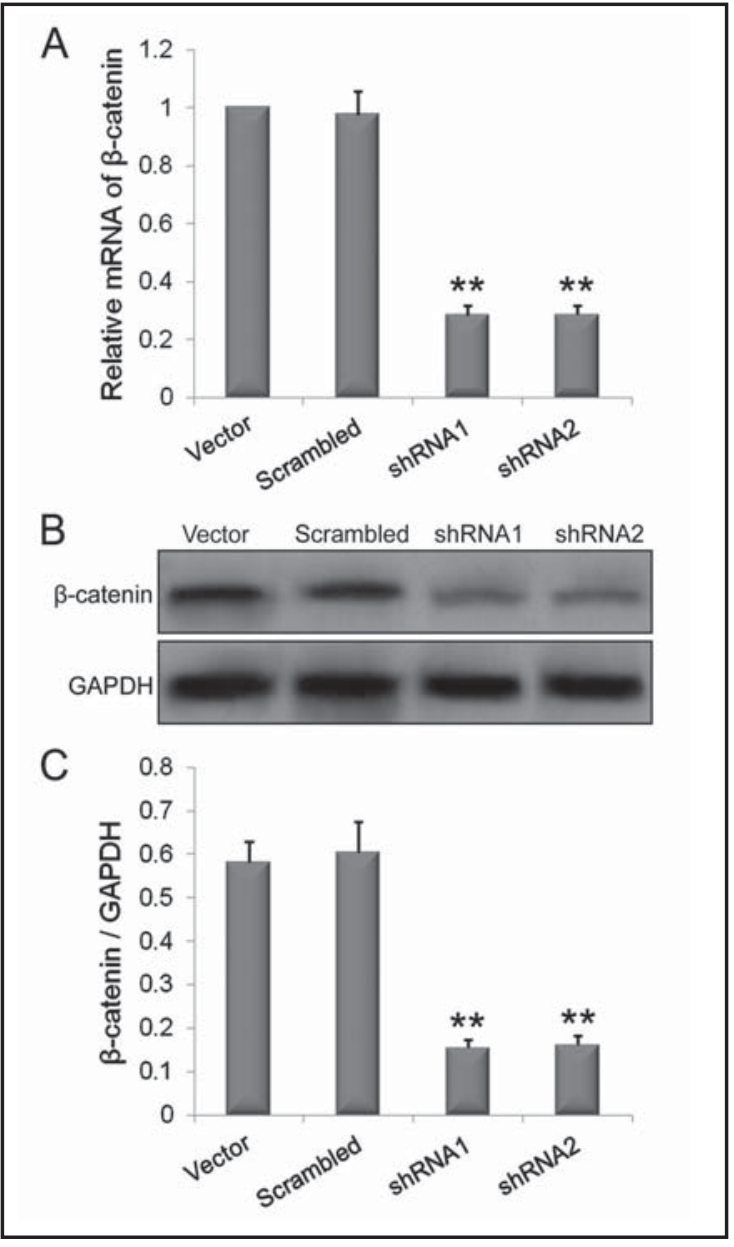

showed an approximately 4-fold decrease in $\beta$-catenin protein level compared to that in the empty vector or scrambled shRNA transfected controls $(\mathrm{p}<0.01)$ (Fig. 3C).

Knockdown of $\beta$-catenin abolished the effect of high phosphate and BMP-2 on VSMC apoptosis and calcification

To further examine the involvement of the Wnt/ $\beta$-catenin pathway in the differentiation of VSMCs, apoptosis and the expression of different markers were assessed in cells treated or not with shRNA against $\beta$-catenin and stimulated with high concentrations of phosphate or BMP-2 for 3 or 7 days. High phosphate and BMP-2 significantly increased the percentage of apoptotic VSMCs by approximately 12 -fold in empty vector or scrambled shRNA transfected controls $(\mathrm{p}<0.01)$, whereas knockdown of $\beta$-catenin significantly weaken this effect $(\mathrm{p}<0.05)$ (Fig. 4A). qRT-PCR analysis showed that knockdown of $\beta$-catenin significantly reversed the downregulation of the mRNA expression of SM $22 \alpha$ and the upregulation of osteocalcin, Msx2, Runx2 and Pit1 caused by high phosphate and BMP-2. In the case of osteocalcin, Msx2, Runx2 and Pit1, $\beta$-catenin silencing restored mRNA expression to a level comparable to that of the untreated controls ( $p<0.05$ ) (Fig. 4B). Similar effects were obtained at the protein level by western blotting and radioimmunoassay (Fig 4C, D and E).

The induction of vascular calcification by BMP-2 is mediated by $\beta$-catenin signaling

To further explore the role of the Wnt/ $\beta$-catenin pathway in the osteoblastic differentiation of VSMCs, ALP activity and calcium deposition were measured in cells treated with or without shRNA against $\beta$-catenin. Phosphate and BMP-2 treatment for 14 days 


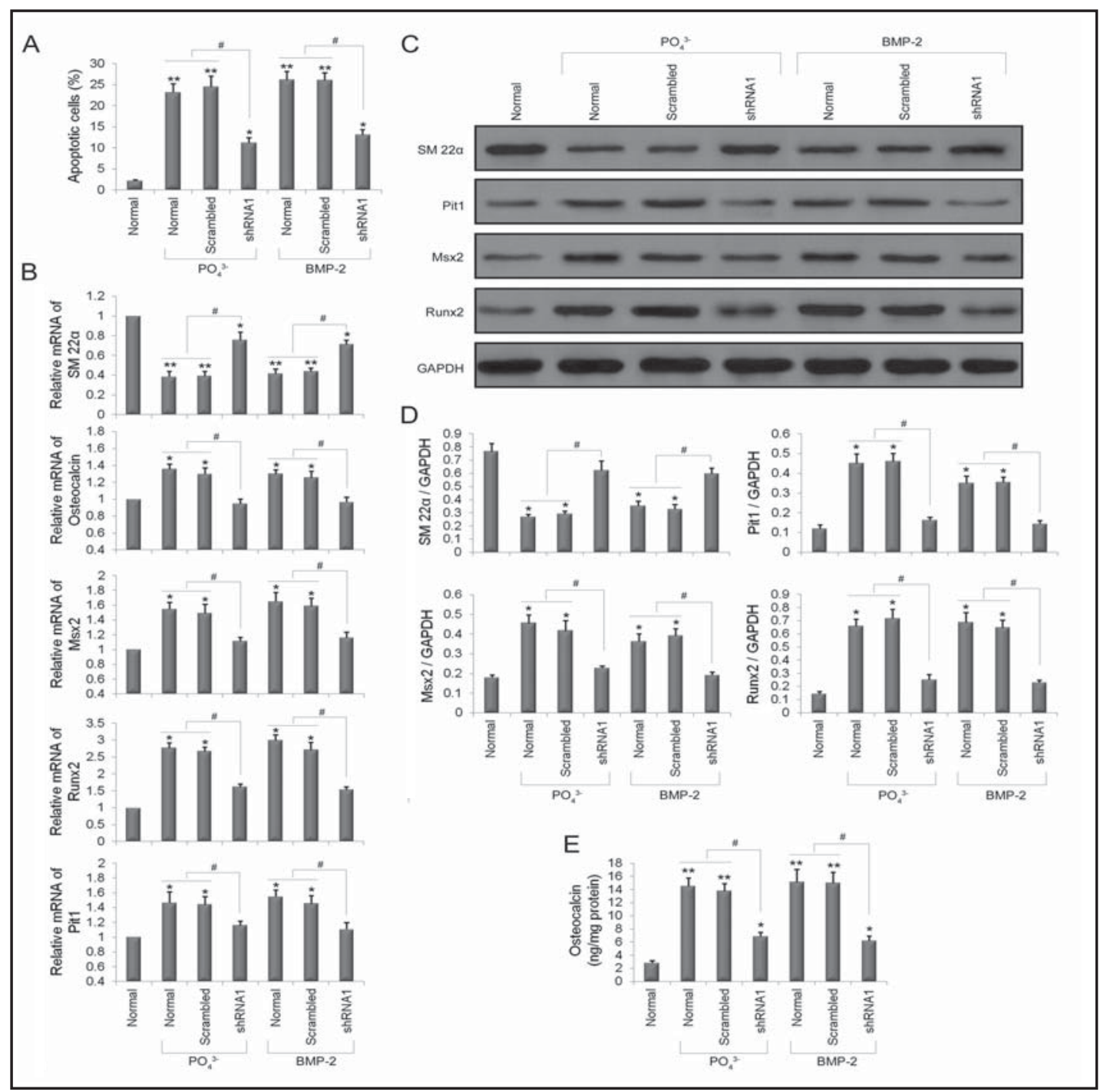

Fig. 4. Effects of $\beta$-catenin knockdown on high phosphate and BMP-2 induced vascular smooth muscle cell apoptosis and calcification. (A) Normal VSMCs or VSMCs transfected with scrambled shRNA or $\beta$-catenin shRNA1 were treated with high-phosphate $(2.5 \mathrm{mM})$ or BMP-2 $(50 \mathrm{ng} / \mathrm{ml})$ for 3 days and subjected to the TUNEL assay. The percentage of apoptotic nuclei was calculated. VSMCs without any treatment served as normal controls. ${ }^{*} \mathrm{p}<0.05,{ }^{* *} \mathrm{p}<0.01$ compared to the normal control, $\# \mathrm{p}<0.05$. (B-E) VSMCs were treated as described in (A) for 7 days. (B) mRNA levels of SM 22 $\alpha$, osteocalcin, Msx2, Runx2 and Pit1 were detected by q RT-PCR and normalized to GAPDH expression. Data are expressed as fold-change relative to the normal control. (C) Protein levels of SM 22 $\alpha$, Pit1, Msx2 and Runx2 were assessed by western blotting with GAPDH as the loading control. (D) Quantification of protein levels was performed by densitometry and normalized to the level of GAPDH. (E) Osteocalcin secretion was measured by radioimmunoassay. ${ }^{*} \mathrm{p}<0.05,{ }^{* *} \mathrm{p}<0.01$ compared to the normal control, $\# \mathrm{p}<0.05$.

significantly $(\mathrm{p}<0.01)$ increased ALP activity (Fig. 5A) and calcium deposition (Fig. 5B) in empty vector or scrambled shRNA infected VSMCs, whereas silencing of $\beta$-catenin significantly reversed these effects $(\mathrm{p}<0.05)$. Alizarin red staining of VSMCs treated as indicated above showed a significant increase in the number of positively stained cells in empty vector and scrambled shRNA transfected cells in response to phosphate and BMP-2, whereas this effect was significantly attenuated in VSMCs infected with shRNA against $\beta$-catenin (Fig. $5 \mathrm{C}$ ). Taken together, these results indicate that BMP-2 induces VC via a mechanism involving the Wnt $/ \beta$ catenin pathway. 


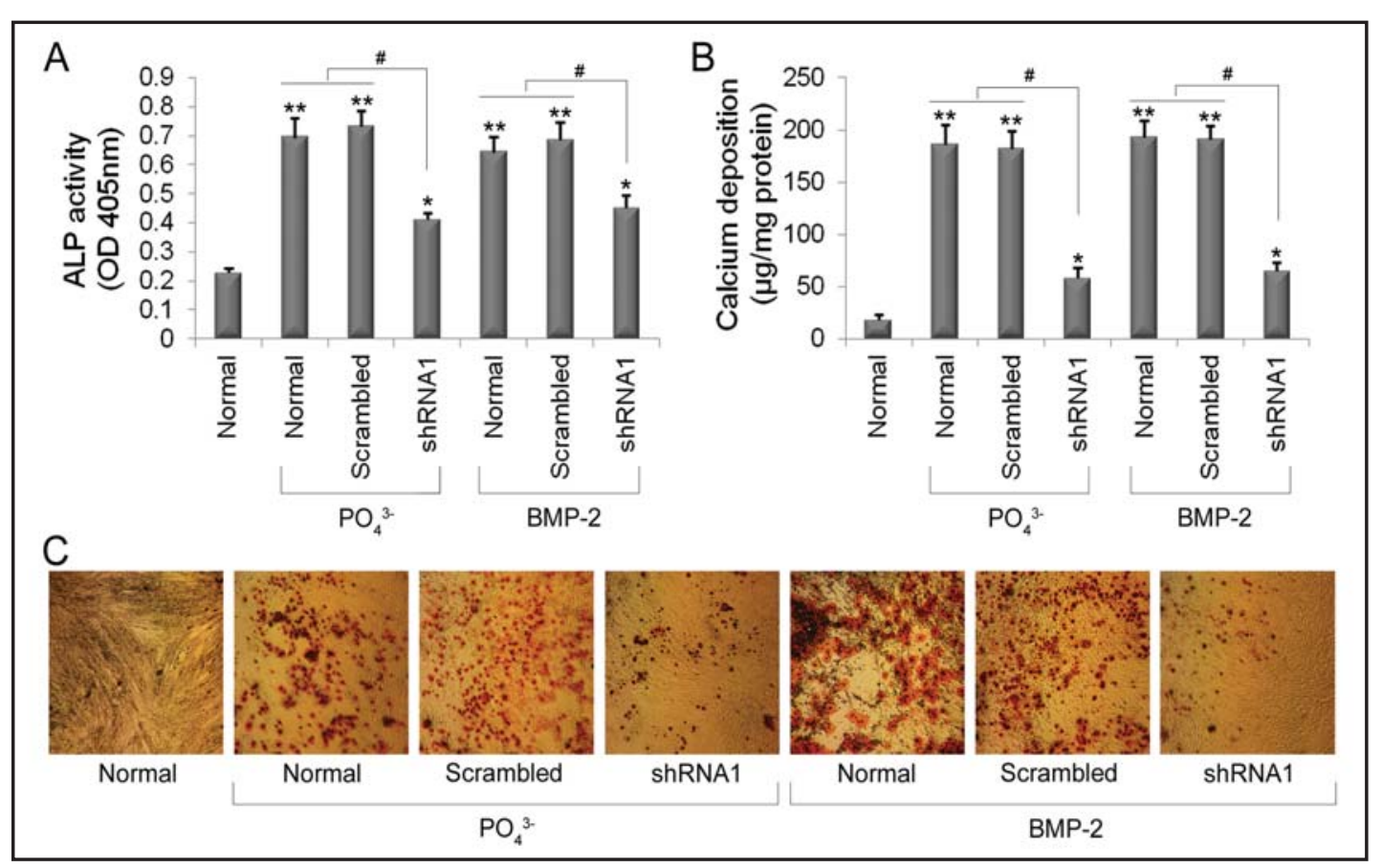

Fig. 5. Involvement of the $\beta$-catenin signaling pathway in BMP-2 induced vascular calcification. Normal VSMCs or VSMCs transfected with scrambled shRNA or $\beta$-catenin shRNA1 were treated with high-phosphate $(2.5 \mathrm{mM})$ or BMP-2 (50 ng/ml) for 14 days. (A) ALP activity at OD $405 \mathrm{~nm}$ was measured. ${ }^{*} \mathrm{p}<0.05,{ }^{* *} \mathrm{p}<0.01$ compared to the normal control, \#p<0.05. (B) Calcium levels were determined in VSMCs treated as indicated. ${ }^{*} \mathrm{p}<0.05,{ }^{* *} \mathrm{p}<0.01$ compared to the normal control, $\# \mathrm{p}<0.05$. (C) Representative photomicrographs of Alizarin red staining of VSMCs in various groups.

\section{Discussion}

The high frequency of cardiovascular disease in CKD has been associated with VC as a predictor of subsequent vascular mortality [26]. VC in CKD is associated with oxidative stress, uremia and hyperphosphatemia leading to the formation of osteoblast-like cells in the vessel walls. Furthermore, the recruitment of progenitor cells and the expression of transcription factors essential for their osteoblastic differentiation, such as Runx2 and Msx2, promote VC in kidney disease. Despite significant advances in our understanding of the process of VC in patients with kidney disease, the factors involved and the exact mechanism remain unclear. In the present study, elevated serum BMP-2 levels in patients with CKD led to an analysis of the effects of BMP-2 and high phosphate on the osteogenic differentiation of VSMCs and the molecular mechanisms underlying VC in CKD.

Previous studies have shown that VSMCs cultured in high concentrations of phosphate undergo osteogenic transformation and calcification $[27,28]$, and the role of BMPs in the regulation of osteoblastic differentiation of VSMCs and VC has been studied extensively [2, 29]. In the present study, we showed that exposure of VSMCs to high phosphate increased the expression of BMP-2 and calcium deposition, and induced VSMC apoptosis in parallel with the differentiation into an osteoblastic phenotype. Increased concentrations of BMP-2 in uremic serum were shown to upregulate Runx2 expression and promote the calcification of VSMCs [30]. In CKD, inflammation plays an important role in VC in part by upregulating the expression of BMP-2 [31]. A link between oxidative stress, BMP-2 expression and VC in CKD was recently proposed by Dalfino et al., who showed that oxidative stress promotes the differentiation of VSMCs by stimulating the release of BMP-2 by endothelial cells [11]. These results were confirmed by in vivo experiments showing that in CKD patients, serum phosphate concentration and serum levels of BMP-2 are independently associated 


\section{Cellular Physiology and Biochemistry}

Cell Physiol Biochem 2014;34:2049-2060

\begin{tabular}{l|l}
\hline DOI: $10.1159 / 000366400$ & (C) 2014 S. Karger AG, Basel
\end{tabular}

www.karger.com/cpb

Rong et al.: BMP-2 and Wnt/ $\beta$-Catenin Pathway in CKD

with arterial stiffness. These results confirmed previous findings showing that increased phosphate uptake and upregulation of Pit- 1 mediate the BMP-2 regulation of VC [32]. These results support the findings of the present study clarifying the role of BMP-2 expression and increased phosphate uptake on VC in CKD.

Bone derived factors and the pathways that regulate their expression have recently been placed at the center of cardiovascular disease associated with CKD [33]. The Wnt/ $\beta$-catenin signaling pathway is critical for the osteogenic commitment of mesenchymal cells and has been shown to be activated during VC [24, 34]. In diabetic mice, Msx promotes the nuclear localization of $\beta$-catenin, enhances Wnt signaling and induces osteoblast differentiation and osteogenic calcification [24]. Alterations in the Wnt/ $\beta$-catenin signaling pathway have been implicated in the development of CKD [35]. A recent study showed that Klotho, a coreceptor of fibroblast growth factor-23 that functions as an inhibitor of Wnt signaling, is deficient in CKD [36]. Wnt/ $\beta$-catenin signaling, which plays an important role in the formation of nephrons and kidney development, is activated in various CKDs including diabetic nephropathy, polycystic kidney disease and obstructive nephropathy $[37,38]$. In the present study, we examined a possible link between BMP-2, VC and the activity of the Wnt/ $\beta$-catenin signaling pathway in CKD, and showed that high phosphate upregulated $\beta$-catenin in parallel with the induction of VSMC apoptosis. Exogenous BMP-2 increased $\beta$-catenin levels and promoted the differentiation of VSMCs into an osteogenic phenotype, whereas silencing of $\beta$-catenin reversed the effect of high phosphate and BMP-2 on VSMC apoptosis and osteogenic differentiation. The inhibition of VSMC calcification by $\beta$-catenin silencing indicates that the osteogenic differentiation of VSMCs induced by BMP-2 occurs via a mechanism involving the activation of Wnt $/ \beta$-catenin signaling. Our results thus provide a possible mechanism by which alterations in Wnt/ $\beta$-catenin signaling play a role in the pathogenesis of CKD by affecting the osteogenic differentiation of vascular smooth muscle cells.

In conclusion, in the present study, we showed that BMP-2 promotes the differentiation of VSMCs into an osteoblastic phenotype and this effect was reversed by $\beta$-catenin knockout, implying the involvement of the Wnt/ $\beta$-catenin signaling pathway in the BMP-2 induced calcification and osteogenic differentiation of VSMCs. Our findings link VC in CKD to BMP-2 expression and the activity of the Wnt/ $\beta$-catenin pathway and suggest novel targets for the treatment of kidney diseases.

\section{Acknowledgements}

This study was supported by grants from the National Natural Science Foundation of China (No. 81200542).

\section{References}

1 Furmanik M, Shanahan C: Er stress in vascular calcification. Heart 2013;99 Suppl 2:A101-102.

-2 Demer LL, Tintut Y: Vascular calcification: Pathobiology of a multifaceted disease. Circulation 2008;117:2938-2948.

- 3 Nakano-Kurimoto R, Ikeda K, Uraoka M, Nakagawa Y, Yutaka K, Koide M, Takahashi T, Matoba S, Yamada H, Okigaki M, Matsubara H: Replicative senescence of vascular smooth muscle cells enhances the calcification through initiating the osteoblastic transition. Am J Physiol Heart Circ Physiol 2009;297:H1673-1684.

-4 Dhore CR, Cleutjens JP, Lutgens E, Cleutjens KB, Geusens PP, Kitslaar PJ, Tordoir JH, Spronk HM, Vermeer C, Daemen MJ: Differential expression of bone matrix regulatory proteins in human atherosclerotic plaques. Arterioscler Thromb Vasc Biol 2001;21:1998-2003.

-5 Kestenbaum BR, Adeney KL, de Boer IH, Ix JH, Shlipak MG, Siscovick DS: Incidence and progression of coronary calcification in chronic kidney disease: The multi-ethnic study of atherosclerosis. Kidney Int 2009;76:991-998. 


\section{Cellular Physiology and Biochemistry}

Cell Physiol Biochem 2014;34:2049-2060

\begin{tabular}{l|l}
\hline DOI: $10.1159 / 000366400$ & (C) 2014 S. Karger AG, Basel
\end{tabular}

Published onlıne: November 28, $2014 \quad$ www.karger.com/cpb

Rong et al.: BMP-2 and Wnt/ $\beta$-Catenin Pathway in CKD

6 Tonelli M, Curhan G, Pfeffer M, Sacks F, Thadhani R, Melamed ML, Wiebe N, Muntner P: Relation between alkaline phosphatase, serum phosphate, and all-cause or cardiovascular mortality. Circulation 2009;120:1784-1792.

7 Jono S, McKee MD, Murry CE, Shioi A, Nishizawa Y, Mori K, Morii H, Giachelli CM: Phosphate regulation of vascular smooth muscle cell calcification. Circ Res 2000;87:E10-17.

8 Lomashvili KA, Cobbs S, Hennigar RA, Hardcastle KI, O'Neill WC: Phosphate-induced vascular calcification: Role of pyrophosphate and osteopontin. J Am Soc Nephrol 2004;15:1392-1401.

9 Villa-Bellosta R, Bogaert YE, Levi M, Sorribas V: Characterization of phosphate transport in rat vascular smooth muscle cells: Implications for vascular calcification. Arterioscler Thromb Vasc Biol 2007;27:10301036.

10 Li X, Yang HY, Giachelli CM: Role of the sodium-dependent phosphate cotransporter, pit-1, in vascular smooth muscle cell calcification. Circ Res 2006;98:905-912.

11 Dalfino G, Simone S, Porreca S, Cosola C, Balestra C, Manno C, Schena FP, Grandaliano G, Pertosa G: Bone morphogenetic protein-2 may represent the molecular link between oxidative stress and vascular stiffness in chronic kidney disease. Atherosclerosis 2010;211:418-423.

12 Go AS, Chertow GM, Fan D, McCulloch CE, Hsu CY: Chronic kidney disease and the risks of death, cardiovascular events, and hospitalization. N Engl J Med 2004;351:1296-1305.

13 Stompor T: Coronary artery calcification in chronic kidney disease: An update. World J Cardiol 2014;6:115129.

14 Jimbo R, Shimosawa T: Cardiovascular risk factors and chronic kidney disease-fgf23: A key molecule in the cardiovascular disease. Int J Hypertens 2014;2014:381082.

15 Covic A, Kanbay M, Voroneanu L, Turgut F, Serban DN, Serban IL, Goldsmith DJ: Vascular calcification in chronic kidney disease. Clin Sci (Lond) 2010;119:111-121.

16 Moe SM, Chen NX: Mechanisms of vascular calcification in chronic kidney disease. J Am Soc Nephrol 2008;19:213-216.

17 Martinez-Moreno JM, Munoz-Castaneda JR, Herencia C, Oca AM, Estepa JC, Canalejo R, Rodriguez-Ortiz ME, Perez-Martinez P, Aguilera-Tejero E, Canalejo A, Rodriguez M, Almaden Y: In vascular smooth muscle cells paricalcitol prevents phosphate-induced wnt/beta-catenin activation. Am J Physiol Renal Physiol 2012;303:F1136-1144.

18 Clevers H: Wnt/beta-catenin signaling in development and disease. Cell 2006;127:469-480.

19 Mbalaviele G, Sheikh S, Stains JP, Salazar VS, Cheng SL, Chen D, Civitelli R: Beta-catenin and bmp-2 synergize to promote osteoblast differentiation and new bone formation. J Cell Biochem 2005;94:403-418.

20 Johnson ML, Kamel MA: The wnt signaling pathway and bone metabolism. Curr Opin Rheumatol 2007;19:376-382.

21 Gaur T, Lengner CJ, Hovhannisyan H, Bhat RA, Bodine PV, Komm BS, Javed A, van Wijnen AJ, Stein JL, Stein GS, Lian JB: Canonical wnt signaling promotes osteogenesis by directly stimulating runx2 gene expression. J Biol Chem 2005;280:33132-33140.

22 Mikhaylova L, Malmquist J, Nurminskaya M: Regulation of in vitro vascular calcification by bmp4, vegf and wnt3a. Calcif Tissue Int 2007;81:372-381.

-23 Mizobuchi M, Towler D, Slatopolsky E: Vascular calcification: The killer of patients with chronic kidney disease. J Am Soc Nephrol 2009;20:1453-1464.

-24 Shao JS, Cheng SL, Pingsterhaus JM, Charlton-Kachigian N, Loewy AP, Towler DA: Msx2 promotes cardiovascular calcification by activating paracrine wnt signals. J Clin Invest 2005;115:1210-1220.

25 King KE, Iyemere VP, Weissberg PL, Shanahan CM: Kruppel-like factor 4 (klf4/gklf) is a target of bone morphogenetic proteins and transforming growth factor beta 1 in the regulation of vascular smooth muscle cell phenotype. J Biol Chem 2003;278:11661-11669.

-26 Foley RN, Parfrey PS, Sarnak MJ: Clinical epidemiology of cardiovascular disease in chronic renal disease. Am J Kidney Dis 1998;32:S112-119.

27 Ciceri P, Volpi E, Brenna I, Arnaboldi L, Neri L, Brancaccio D, Cozzolino M: Combined effects of ascorbic acid and phosphate on rat vsmc osteoblastic differentiation. Nephrol Dial Transplant 2012;27:122-127.

28 Villa-Bellosta R, Millan A, Sorribas V: Role of calcium-phosphate deposition in vascular smooth muscle cell calcification. Am J Physiol Cell Physiol 2011;300:C210-220.

-29 Hruska KA, Mathew S, Saab G: Bone morphogenetic proteins in vascular calcification. Circ Res 2005;97:105-114. 
-30 Chen NX, Duan D, O'Neill KD, Wolisi GO, Koczman JJ, Laclair R, Moe SM: The mechanisms of uremic serum-induced expression of bone matrix proteins in bovine vascular smooth muscle cells. Kidney Int 2006;70:1046-1053.

31 Fukui N, Ikeda Y, Ohnuki T, Hikita A, Tanaka S, Yamane S, Suzuki R, Sandell LJ, Ochi T: Pro-inflammatory cytokine tumor necrosis factor-alpha induces bone morphogenetic protein-2 in chondrocytes via mrna stabilization and transcriptional up-regulation. J Biol Chem 2006;281:27229-27241.

32 Li X, Yang HY, Giachelli CM: Bmp-2 promotes phosphate uptake, phenotypic modulation, and calcification of human vascular smooth muscle cells. Atherosclerosis 2008;199:271-277.

33 Vervloet MG, Massy ZA, Brandenburg VM, Mazzaferro S, Cozzolino M, Urena-Torres P, Bover J, Goldsmith D: Bone: A new endocrine organ at the heart of chronic kidney disease and mineral and bone disorders. Lancet Diabetes Endocrinol 2014;2:427-436.

34 Komori T: Signaling networks in runx2-dependent bone development. J Cell Biochem 2011;112:750-755.

35 Al-Chaqmaqchi HA, Moshfegh A, Dadfar E, Paulsson J, Hassan M, Jacobson SH, Lundahl J: Activation of wnt/beta-catenin pathway in monocytes derived from chronic kidney disease patients. PLoS One 2013;8:e68937.

-36 Hu MC, Kuro-o M, Moe OW: Klotho and chronic kidney disease. Contrib Nephrol 2013;180:47-63.

37 He W, Tan RJ, Li Y, Wang D, Nie J, Hou FF, Liu Y: Matrix metalloproteinase-7 as a surrogate marker predicts renal wnt/beta-catenin activity in ckd. J Am Soc Nephrol 2012;23:294-304.

-38 Carroll TJ, Park JS, Hayashi S, Majumdar A, McMahon AP: Wnt9b plays a central role in the regulation of mesenchymal to epithelial transitions underlying organogenesis of the mammalian urogenital system. Dev Cell 2005;9:283-292. 